\title{
EDITORIAL
}

\section{The Atlántida 2008 Cave Diving Expedition}

\author{
Stefan Koenemann • Thomas M. Iliffe
}

Received: 1 April 2009 / Accepted: 17 June 2009 / Published online: 29 July 2009

(C) Senckenberg, Gesellschaft für Naturforschung and Springer 2009

This special issue of Marine Biodiversity features seven papers that represent the results of the Atlántida 2008 Cave Diving Expedition. This scientific expedition, carried out from 11 to 25 March 2008, involved a series of exploratory cave dives using closed circuit rebreathers to investigate the world's longest undersea lava tube located on Lanzarote, Canary Islands, Spain. Our principal scientific objectives were to 1) collect several specimens of the remipede crustacean Speleonectes ondinae (Garcia-Valdecasas, 1984) as part of an ongoing molecular genetics investigation, 2) determine temporal (tidal) fluctuations in water quality parameters along the length of the lava tube, 3) collect interstitial fauna from the Montaña de Arena, a pile of freshly depositing carbonate sand located deep within the cave, and 4) photographically document the fauna and the key features of the submarine lava tube. To our surprise, we encountered an astoundingly rich subterranean aquatic fauna that included new species of remipede crustaceans and polychaete annelid worms. As a result of our investigations, we here present a comprehensive description of a unique lava tube ecosystem, including new insights in its ecology, biodiversity, and environmental variables.

Members of the Atlántida 2008 Cave Diving Expedition included divers Jill Heinerth, Thomas Iliffe, James Rossi, and Terrence Tysall, in addition to non-diving scientists Renee Bishop (Penn State University), Stefan Koenemann (University of Veterinary Medicine Hannover), Alejandro Martínez (Universidad de La Laguna), and Horst and Ulrike Wilkens (University of Hamburg). We are particularly grateful to the local Environmental and Touristic Services of the Cabildo de Lanzarote for allowing us access to the Túnel de la Atlántida and collect samples in protected areas, and the Consejería de Medio Ambiente of the Canary Government for providing the permits to collect endangered species. In addition, we are indebted to our Spanish colleagues Pedro Oromí and Jorge Núñez of the Universidad de La Laguna for their support and assistance with this research.

S. Koenemann $(\bowtie)$

University of Veterinary Medicine Hannover,

Hannover, Germany

e-mail: stefan.koenemann@tiho-hannover.de

T. M. Iliffe

Texas A\&M University at Galveston,

Galveston, TX, USA

e-mail: iliffet@tamug.edu 